\title{
Awareness about breast and cervical cancers among nursing students in Beni-Suef University
}

\author{
Amel Abd-Elazim Mohamed ${ }^{1}$, Hanan Elzeblawy Hassan*2, Wafaa Mostafa Ahmed Gamel ${ }^{3}$, Ahmed Emadeldin Arafa ${ }^{4}$ \\ ${ }^{1}$ Department of Community Health Nursing, Faculty of Nursing, Beni-Suef University, Egypt \\ ${ }^{2}$ Department of Maternal \& Newborn Health Nursing, Faculty of Nursing, Beni-Suef University, Egypt \\ ${ }^{3}$ Department of Maternal and Neonatal Health Nursing, Faculty of Nursing, Fayoum University, Egypt \\ ${ }^{4}$ Department of Public Health, Faculty of Medicine, Beni-Suef University, Egypt
}

Received: August 7, 2018

DOI: $10.5430 /$ jnep.v9n5p44
Accepted: December 30, 2018 Online Published: January 15, 2019

URL: https://doi.org/10.5430/jnep.v9n5p44

\begin{abstract}
Background and objective: Breast and cervical cancers represent a public health concern since they result in high mortality and disability rates. The aim of our study was to assess the knowledge of nursing students in Beni-Suef University about both Breast and cervical.

Subjects and methods: A total of 500 students representing all scholastic years from the Technical Institute of Nursing (both 2 years of post-high school nursing education), Beni-Suef University, Egypt, participated in this study that was conducted during the 1 st semester of the academic year 2017/2018. The knowledge of the students was assessed using a self-administered questionnaire. The assessment included knowledge of students about 4 aspects; risk factors, manifestations, screening, and management of breast and cervical cancers.

Results: The mean age of the students was $19.2 \pm 0.7$ years, and most of them (77.6\%) were females. Precisely, $43 \%$ had optimal knowledge about breast cancer; $43.8 \%$ risk factors, $52.4 \%$ manifestations, $27.8 \%$ screening, and $48 \%$ management, while only $29 \%$ of students had optimal knowledge about cervical cancer; $21.8 \%$ risk factors, $38.2 \%$ manifestations, $12.4 \%$ screening, and 43.6\% management. None of the studied personal characteristics showed association with the knowledge of students whether regarding breast or cervical cancers $(p>.05)$. Healthcare givers, TV, and the Internet were the most commonly reported sources of knowledge about breast and cervical cancers: $42 \%, 33.2 \%$, and $21.2 \%$, respectively.

Conclusion and recommendations: Students lacked the required knowledge about breast and cervical cancers. In particular, knowledge scores of students about screening for both cancers were the lowest. Further studies should focus on improving the knowledge of nursing students using awareness programs or educational modules.
\end{abstract}

Key Words: Knowledge, Breast cancer, Cervical cancer, Nursing students

\section{INTRODUCTION}

Cancer is a major worldwide public health concern. Breast cancer (BC) is the most common cancer among women and results into the highest fatalities. ${ }^{[1]}$ According to American Cancer Society Facts (A.C.S.F.) in 2017, a total of 63,410 in situ cases, 252,710 invasive cases, and 40,610 deaths were registered. ${ }^{[2]}$

In Egypt, as reported by the National Cancer Registry Program (NCRP), BC occupied the 2nd position after liver cancer which both accounting for about $45 \%$ of all cancers in

\footnotetext{
*Correspondence: Hanan Elzeblawy Hassan; Email: nona_nano_1712@yahoo.com; Address: Maternal \& Newborn Health Nursing, Faculty of Nursing, Beni-Suef University, Egypt.
} 
both sexes in 2014. It represented $38.8 \%$ of all cancers affecting women with an incidence of 35.8/100,1000 between 2008 and 2011. ${ }^{[3,4]}$ Moreover, Egyptian study (2014) reported that 19,105 women diagnosed with Breast cancer. ${ }^{[5]}$

Early diagnosis of BC can offer more options of treatment, improve the prognosis, and prolong the lifetime. Since breast cancer produces no symptoms in early stages, screening is crucial for early detection. It is also suggested that early diagnosis is the most effective way to reduce the burden of mortalities and morbidities attributed to this cancer. ${ }^{[6,7]}$

Currently, the primary preventive measures of BC are limited and assuming the significance of early detection and diagnosis at the early stage to enhance women's quality of life (QOL) and decrease the associated mortality. Thus, screening is the paramount secondary preventive measure for attaining such goals. ${ }^{[8,9]}$ Typically, screening for breast cancer targets examination of healthy individuals when no apparent manifestations are present with the aim of early diagnosis. ${ }^{[6,7]}$ Notably, WHO (2018) reported that around $30 \%$ to $50 \%$ of cancer cases can be inhibited by screening measures and avoidance of mentioned risk factors. ${ }^{[10]}$ The suggested screening approaches for early identification of BC are: Breast Self-Examination (BSE), clinical breast examination (CBE), and mammography. ${ }^{[9-11]}$ However, mammography screening is the gold standard technique for the early recognition of $\mathrm{BC}$, WHO recommended $\mathrm{BSE}$, as an individual measure, for raising women's awareness regarding $\mathrm{BC}$ risks and its early detection. ${ }^{[10,11]}$

Cervical cancer (CC) is a significant health issue worldwide $^{[12]}$ and the 3rd most common cancer in the world. ${ }^{[13]}$ It constitutes, also, a public health concern, however less burdensome compared to breast cancer. The incidences and mortalities from cervical cancer vary widely between studies. ${ }^{[1,14]}$ In Egypt, cervical cancer represented less than $1.2 \%$ of all cancers that affected females between 2008 and 2011. ${ }^{[3]}$ However, 752 cases diagnosed with cervical cancer in $2014,{ }^{[13]}$ Egyptian studies reported wide varied estimates of the prevalence of pre-invasive cervical lesions ranging from $1.0 \%$ to $8.0 \% .^{[15]}$

Early diagnosis of CC plays a pivotal role in prompt and successful management. ${ }^{[12,16]}$ The Papanicolaou test (Papsmear test) is widely used in developed countries to screen for CC. ${ }^{[14,15]}$ It is an effective, low-cost, harmless, easily applicable and high-sensitive method of early diagnosis which also reduces the burden of treatment, morbidities, and mortalities. ${ }^{[16,17]}$

In order to combat both cancers, nurses have two main roles; awareness role and screening role. It is highly important for

Published by Sciedu Press nurses to spread public health awareness about the prevention and early diagnosis of breast and cervical cancers, and they should also participate in screening campaigns for both cancers. ${ }^{[18]}$ Therefore, it is crucial for nursing students to be aware of the necessary knowledge about both cancers in order to conduct their future tasks, as nurses, appropriately.

\subsection{Significance of the study}

Although breast and cervical cancers result in graving consequences, little is known about knowledge of nursing students in Beni-Suef University regarding the risk factors, manifestations, screening, and management of both cancers. We believe that knowledgeable nurses could help not only in awareness programs but in screening campaigns as well.

\subsection{Aim of the study}

The aim of this study was to assess the knowledge of nursing students in Beni-Suef University, Egypt, about causes, risk factors, manifestations, early detection \& screening, and management of both breast \& cervical cancers.

\subsection{Research question}

What is the level of knowledge of nursing students in BeniSuef University about causes and risk factors, manifestations, early detection and screening procedures, and management of both breast and cervical cancers?

\section{METHODOLOGY}

\subsection{Study design}

A cross-sectional design was adopted.

\subsection{Setting and time frame}

A total of 500 nursing students representing all scholastic years of the Technical Institute of Nursing, (both 2 years of post-high school nursing education), Beni-Suef University participated in this study. The assessment of students' knowledge has been done during the 1 st semester of the academic year 2017/2018.

\subsection{Sampling}

The sample size was calculated using Epi-Info version 7 Stat Calc, [Center for Disease Control (CDC), WHO], based on the following criteria; optimal knowledge $25 \%$, the confidence level of $95 \%$, the margin of error of $5 \%$ and the non-response rate of $25 \%$.

A total of 622 nursing students was registered at The Technical Institute of Nursing, and all of them were invited to participate in the study and received their questionnaires. Of the 622 questionnaires, 544 came back giving us a response rate of $87.5 \%$. Then 44 questionnaires were excluded be- 
cause of incompleteness to end in 500 questionnaires that were included in the analysis.

\subsection{Fieldwork and data collection}

After reviewing the previous studies, researchers designed an Arabic-language questionnaire of 4 sections. Section 1 included the socio-demographic characteristics of the students; name, age, sex, residence, marital status, family history of breast or cervical cancers, and their readiness, and keenness to assess their awareness of breast and cervical cancer.

Section 2 assessed the knowledge of students about breast cancer using multi-choice questions, and true and false questions. This section included 4 divisions; risk factors, manifestations, screening, and management of breast cancer, and every division included 5 questions.

Scoring system: True answers were given a score of 1, making the score of each division 5, and the total score was 20 . Students who achieved $60 \%$ or more (3/5 in divisions or $12 / 20$ totally) were considered of optimal knowledge.

The risk factors division evaluated the knowledge of students about the possible roles for family history, fatty diets, ethnicity, alcoholism, early menarche, obesity, hypertension, stress, and use of certain contraceptive methods in the development of breast cancer. The manifestations division had questions about the general and local symptoms and signs that could suspect breast cancer. The screening division included questions about the appropriate age, methods, and regularity of screening. The management division assessed knowledge of students about chemotherapy, radiotherapy, surgical procedures, dietetics, and psychological support.

Section 3 evaluated the knowledge of students about cervical cancer using multi-choice questions, and true and false questions. Similar to the breast cancer section, this section included 4 divisions; risk factors, manifestations, screening, and management of cervical cancer, and every division included 5 questions.

Scoring system: True answers were given a score of 1, making the score of each division 5, and the total score was 20 . Students who achieved $60 \%$ or more $(3 / 5$ in divisions or $12 / 20$ totally) were considered of optimal knowledge.

The risk factors division evaluated the knowledge of students about the possible roles for old age, sexually transmitted infections, smoking, obesity, immunity disorders, and use of certain contraceptive methods in the development of cervical cancer. The manifestations division included questions about the general and local symptoms and signs that could suspect cervical cancer. The screening division included questions about the appropriate age, methods, regularity, and accuracy of screening. The management division assessed 46 knowledge of students about chemotherapy, radiotherapy, surgical procedures, dietetics, and emotional rehabilitation.

Section 4 questioned about the sources that students accessed to acquire information about breast and cervical cancers; TV, Internet, books and magazines, health-caregivers (nurses, doctors, etc), friends and family.

Before distributing the questionnaire for data collection, a pilot study on 50 students was conducted to evaluate the validity \& reliability of the questionnaire. The Cronbach's alpha for reliability was 0.71 , while content validity was assessed by a professor of woman health, maternity, obstetrics \& gynecology nursing and a professor of community health nursing and a professor of public health. Since there were no modifications to the questionnaire after the pilot study and the results were merely close to the final findings, the questionnaires were included in the final sample.

\subsection{Ethical considerations}

The study was conducted in full accordance with the guidelines for the Declaration of Helsinki, and data for participants were collected only after obtaining their verbal consent.

\subsection{Data analysis}

Data entry, verification, and validation were carried out using standard computer software. Data were analyzed using the software, Statistical Package for Social Science (SPSS Inc. Released 2009, PASW Statistics for Windows, version 18.0: SPSS Inc., Chicago, Illinois, USA), then processed and tabulated. Frequency distribution with its percentage $\&$ descriptive statistics with mean \& standard deviation were calculated. Chi-square, $t$-test, correlations were done whenever needed. The graphical presentation included 3-D Clustered Column and Pie chart diagram. $p$ values of less than .05 were considered significant.

\section{RESULTS}

A total of 500 nursing students from Beni-Suef University participated in this study. Their mean age was $19.2 \pm 0.7$ years. The majority of the participants $(77.6 \%)$ were females. More than half (57.6\%) of participants were residing in urban areas, and $42.4 \%$ were living in rural areas. Only $6.4 \%$ were married by the time of the study, and $6.6 \%$ reported a family history of BC and/or CC. A high of $84.4 \%$ was interested in attending awareness sessions or programs about breast and cervical cancers (see Table 1).

Out of the 500 students, 215 (43\%) had optimal knowledge about breast cancer; 219 (43.8\%) risk factors and possible aetiologies, 262 (52.4\%) symptoms and signs, 139 (27.8\%) prevention and early detection, and 240 (48\%) management (see Figure 1). 
Table 1. Socio-demographic characteristics of the participating nursing students

\begin{tabular}{lll}
\hline Socio-demographic characteristics & & Total (n= 500) (\%) \\
\hline Age (Mean \pm SD) years & Male & $19.2 \pm 0.7$ \\
Sex & Female & $112(22.4)$ \\
& Urban & $388(77.6)$ \\
Residence & Rural & $288(57.6)$ \\
& Positive & $212(42.4)$ \\
Family history of breast/cervical cancer & Negative & $33(6.6)$ \\
& Married & $467(93.4)$ \\
Marriage status & Single & $32(6.4)$ \\
Eager to assess the awareness of breast and cervical & Yes & $468(93.6)$ \\
cancer & No & $422(84.4)$ \\
\hline
\end{tabular}

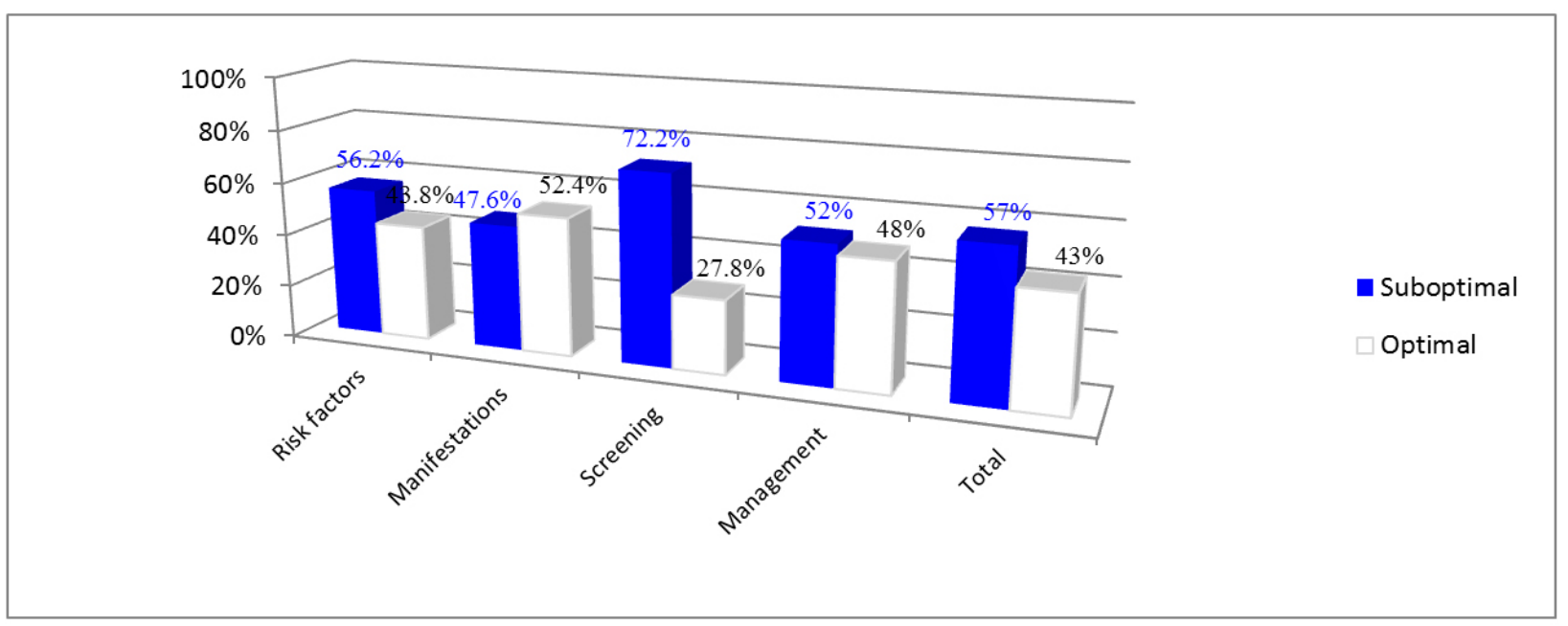

Figure 1. Knowledge of the participating nursing students about breast cancer

However, when students with optimal knowledge about teristics had a statistically significant impact on students' breast cancer were compared to their counterparts with sub- knowledge $(p>.05)$ (see Table 2).

optimal knowledge, none of the studied individual charac-

Table 2. Association between socio-demographic characteristics of the participating nursing students and their knowledge about breast cancer

\begin{tabular}{|c|c|c|c|c|}
\hline Socio-demographic characteristics & & Optimal $(n=215)(\%)$ & Suboptimal $(n=285)(\%)$ & $p$ value \\
\hline Age (Mean \pm SD) years & & $19.1 \pm 0.8$ & $19.2 \pm 0.5$ & .763 \\
\hline \multirow{2}{*}{ Sex } & Male & $50(23.3)$ & $62(21.8)$ & \multirow{2}{*}{.821} \\
\hline & Female & 165 (76.7) & $223(78.2)$ & \\
\hline \multirow{2}{*}{ Residence } & Urban & $122(56.7)$ & $166(58.2)$ & \multirow{2}{*}{.848} \\
\hline & Rural & $73(43.3)$ & 119 (41.8) & \\
\hline \multirow{2}{*}{ Family history } & Positive & $14(6.5)$ & $19(6.7)$ & \multirow{2}{*}{.879} \\
\hline & Negative & 201 (93.5) & 266 (93.3) & \\
\hline \multirow{2}{*}{ Marriage status } & Married & $14(6.5)$ & $18(6.3)$ & \multirow{2}{*}{.892} \\
\hline & Single & 201 (93.5) & 267 (93.7) & \\
\hline \multirow{2}{*}{$\begin{array}{l}\text { Eager to assess the awareness of breast } \\
\text { and cervical cancer }\end{array}$} & Yes & 177 (82.3) & 245 (85.9) & \multirow{2}{*}{.672} \\
\hline & No & $38(17.7)$ & $40(14.1)$ & \\
\hline
\end{tabular}


Regarding the knowledge about cervical cancer, only 145 factors, 191 (38.2\%) manifestations, 62 (12.4\%) screening, (29\%) students had optimal knowledge; 109 (21.8\%) risk and 218 (43.6\%) management (see Figure 2).

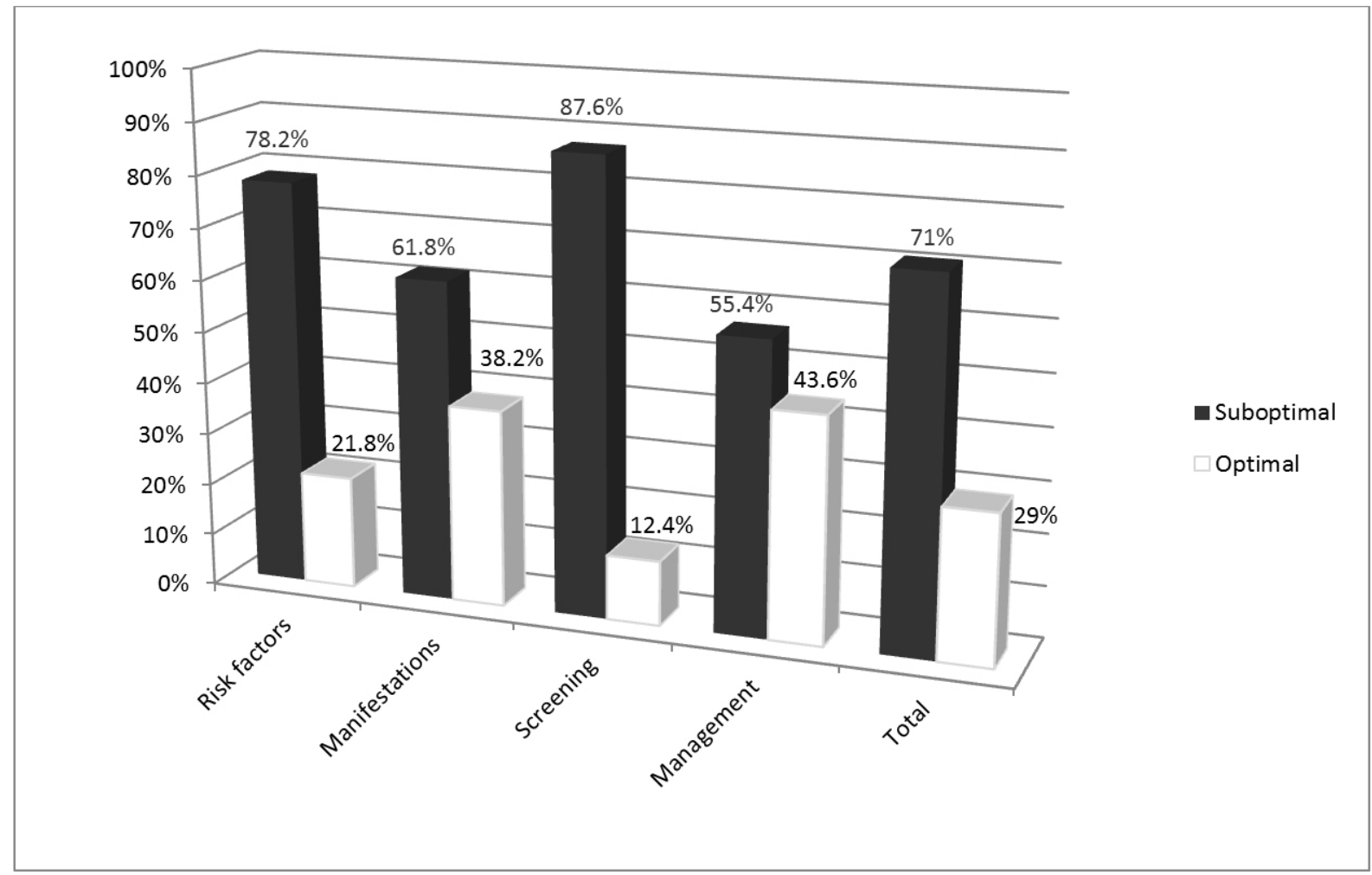

Figure 2. Knowledge of the participating nursing students about cervical cancer

Just like knowledge about breast cancer, the personal char- about cervical cancer $(p>.05)$ (see Table 3). acteristics showed no association with students' knowledge

Table 3. Association between socio-demographic characteristics of the participating nursing students and their knowledge about cervical cancer

\begin{tabular}{|c|c|c|c|c|}
\hline Socio-demographic characteristics & & Optimal $(n=145)(\%)$ & Suboptimal $(n=355)(\%)$ & $p$ value \\
\hline Age (Mean \pm SD) years & & $19.2 \pm 0.6$ & $19.1 \pm 0.9$ & .654 \\
\hline \multirow{2}{*}{ Sex } & Male & $34(23.4)$ & $78(22.0)$ & \multirow{2}{*}{.832} \\
\hline & Female & $111(76.6)$ & $277(78.0)$ & \\
\hline \multirow{2}{*}{ Residence } & Urban & $81(55.9)$ & 207 (58.3) & \multirow{2}{*}{.731} \\
\hline & Rural & $64(44.1)$ & $148(41.7)$ & \\
\hline \multirow{2}{*}{ Family history } & Positive & $6(4.1)$ & $27(7.6)$ & \multirow{2}{*}{.259} \\
\hline & Negative & 139 (95.9) & $328(92.4)$ & \\
\hline \multirow{2}{*}{ Marriage status } & Married & $8(5.5)$ & $24(6.8)$ & \multirow{2}{*}{.764} \\
\hline & Single & 137 (94.5) & $331(93.2)$ & \\
\hline \multirow{2}{*}{$\begin{array}{l}\text { Eager to assess the awareness of cervical } \\
\text { cancer }\end{array}$} & Yes & $127(87.6)$ & $295(83.1)$ & \multirow{2}{*}{.408} \\
\hline & No & $18(13.3)$ & 60 (16.9) & \\
\hline
\end{tabular}

When the participating students were asked about their sources of knowledge about breast and cervical cancers, healthcare givers (doctors, nurses, etc) came on the top of the list with $42 \%$, followed by TV $33.2 \%$ and Internet $21.2 \%$ (see Figure 3). 


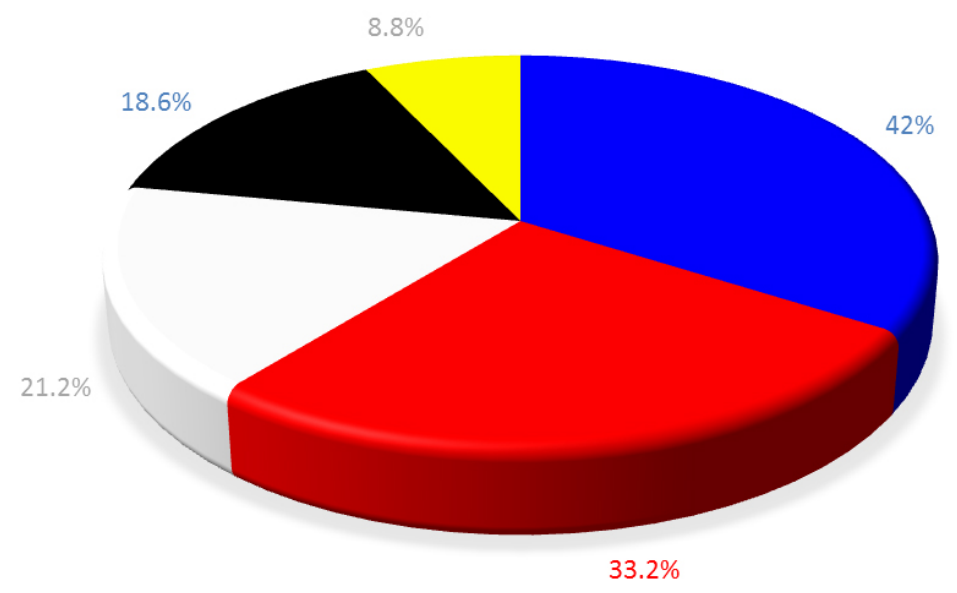

Healthcare givers 回TV

M Internet

Books and Magazines A Family and Friends

Figure 3. Sources of knowledge of the participating nursing students about breast and cervical cancers

\section{Discussion}

Knowledge about cancer is a basic step towards developing a positive approach towards screening for the disease. However, educational barriers resulting from suboptimal knowledge is a major reason for low screening prevalence in developing countries. ${ }^{[19]}$ Hence, this study aimed to evaluate the knowledge of the nursing students at Beni-Suef University about $\mathrm{BC}$ and $\mathrm{CC}$.

Our results revealed that $43.0 \%$ of the participating nursing students had optimal knowledge about breast cancer; $43.8 \%$ risk factors, $52.4 \%$ manifestations, $27.8 \%$ screening, and $48 \%$ management.

In a study over 137 nurses involved in the care of oncology patients in a public university hospital in Brazil, 65.8\% gave correct answers about risk factors of breast cancer. ${ }^{[20]}$ Another study on 281 nurses from Ethiopia showed that $57.8 \%$ of them were knowledgeable about breast cancer; less than $30 \%$ risk factors, $45.2 \%$ signs, $65.9 \%$ screening. ${ }^{[21]}$ Other studies on nurses from Turkey, ${ }^{[22]}$ Singapore $^{[23]}$ and Pakistan ${ }^{[24]}$ showed similar limitations in knowledge about breast cancer. In a cross-sectional study over 301 female university students from Turkey, $65.4 \%$ had a satisfactory knowledge score about screening for BC. ${ }^{[25]}$ A communitybased study on 393 females from Brazil aged 40-69 years and receiving health services, found that almost $50 \%$ did not know any of the risk factors of breast cancer. ${ }^{[26]}$ A study on 38 African American females showed significant deficits in knowledge about breast cancer. ${ }^{[27]}$
This variation in findings can be attributed mainly to using different data collecting methods and adopting various methods of assessment. Further, most of the cited studies were conducted on working nurses while our study targeted nursing students.

In the current study, we did not find a significant association between the age of students and their knowledge about breast cancer and this could be explained by the tight range of age included in our study. Also, having a positive family history did not correlate with knowledge of students about breast cancer. Unlike our findings, previous reports confirmed the role of having a positive family history in determining the knowledge of nurses about breast cancer. ${ }^{[20,21]}$ In regards to cervical cancer, $29 \%$ of students had optimal knowledge about cervical cancer; $21.8 \%$ risk factors, $38.2 \%$ manifestations, $12.4 \%$ screening, and $43.6 \%$ management.

In a study over university students, $55.1 \%$ of them were knowledgeable about prevention of cervical cancer. ${ }^{[25]} \mathrm{An}$ other study on 102 nursing students showed that only $30 \%$ of the had good knowledge about cervical cancer and 30\% were aware of the screening methods. ${ }^{[28]}$ A study from India indicated that majority of the participants $(89.6 \%)$ had good knowledge about risk factors of cervical cancer. ${ }^{[28]}$ Another study on educated young females in Asia concluded that the awareness of cervical cancer was $66 \%$ in India, 58.8\% in Nepal and $57.7 \%$ in Sri Lanka. ${ }^{[29]}$ Also, less than half of the African and Vietnamese American females showed unsatisfactory knowledge about cervical cancer. ${ }^{[27,30]}$ 
The relatively lower rates of optimal knowledge about cervical cancer in our study may be explained by 2 main factors; lacking of the standardized assessment tool and the fact that cervical cancer constitutes a very small proportion of the cancers affecting females in Egypt, so most of the awareness programs do not consider cervical cancer a priority.

It is really worth pointing out that although the knowledge of the nursing students in the current study regarding breast and cervical cancers was unsatisfactory, healthcare-givers was the main source of knowledge for the participants. This point refers to a suggestion that the knowledge of the teaching staff might not be optimal. Previous reports showed different sources of knowledge including nurses, doctors, TV, and social websites, and friends or relatives. ${ }^{[16,20,26,31,32]}$

\section{CONCLUSION AND RECOMMENDATIONS}

In conclusion, the knowledge of the participating nursing students about both cancers was unsatisfactory. Continuing educational programs for nursing students should be conducted regularly to spread knowledge about breast and cervical cancers. Priority should be given to methods of screening and early diagnosis. Further research should be targeted to health-care givers because of their important role in screening programs and spreading health information about breast and cervical cancers.

\section{CONFLicts of INTEREST Disclosure}

The authors declare that there is no conflict of interest.

\section{REFERENCES}

[1] Qalawa SH, Eldeeb A, Hassan H. Young Adult Women's intention regarding breast and cervical cancer screening in Beni-Suef. Scientific Research Journal. 2015; 3(3): 11-24.

[2] American Cancer Society. Breast Cancer Facts \& Figures 2017-2018.

[3] Ibrahim S, Khaled M, Mikhail H, et al. Cancer Incidence in Egypt: Results of the National Population-Based Cancer Registry Program. Journal of Cancer Epidemiology. 2014.

[4] Mohammed F, Shahin M, Youness E, et al. Survivorship in Women Undergoing Gynecological and Breast Cancer Treatment in Upper Egypt: The Impact of Quality of Life Improvement Educational Program. American Research Journal of Gynaecology. 2018; 2(1): $1-28$.

[5] Nady F, Said M, Youness E, et al. Impact of Tailored Educational Program of Quality of Life Improvement on Women Undergoing Breast Cancer Treatment at El-Minia Region, Egypt. American Research Journal of Gynaecology. 2017; 1(1): 1-17.

[6] AydinAvci I, Kumcagiz H, Altinel B, et al. Turkish female academician self-esteem and health beliefs for breast cancer screening. Asian Pac J Cancer Prev. 2014; 15: 155-60. https ://doi .org/10.731 4/APJCP. 2014.15.1.155

[7] Ersin F, Bahar Z. Effects of health promotion models on breast cancer early detection behaviors: a literature review. DokuzEylul Univers Nurs School J. 2012; 5: 28-38.

[8] World Health Organization. Breast cancer: prevention and control. Available: http://www. who.int/cancer/detection/breastc ancer/en/

[9] American College of Obstetricians and Gynaecologists. Practice bulletin no. 122: Breast cancer screening. Obstet Gynecol. 2011; 118 (2 Pt 1): 372-82. PMid:21775869

[10] World Health Organization (WHO). World Cancer Day 2018.Available from: http://www.who.int/cancer/world-cancer-day /2018/en/

[11] American Cancer Society. Breast cancer screening for women at average risk: 2015 guideline update from the American Cancer Society. JAMA, 2015; 314(15): 1599-614. PMid:26501536 https : //doi.org/10.1001/jama.2015.12783
[12] Said S, Hassan H, Sarhan A. Effect of an Educational Intervention on Women's Knowledge and Attitude Regarding Cervical Cancer. American Journal of Nursing Research. 2018; 6(2): 59-66.

[13] Nady F, El-Sherbiny M, Youness E, et al. Effectiveness of Quality of Life Planned Teaching Program on Women Undergoing Gynecologic Cancer Treatment. American Research Journal of Oncology. 2018; 1(1): 1-17.

[14] Hassan H, Bayoumi M, Atwa A. Emotional Distress Associated with Gynecologic and Breast Cancer in Beni-Suef City. International Journal of Science and Research. 2016; 5(2): 1118-1129.

[15] Hassan H, Atwa A. Occupational Stress, Job Satisfaction and Cervical Screening Intention of Maternity Oncology Nurses, Medical Science \& Healthcare Practice. 2017; 1(1): 48-59.

[16] Ozdemir O, Bilgili N. Knowledge and practices of nurses working in an education hospital on early diagnosis of breast and cervix cancers TAF Prev Med Bulletin. 2010; 9: 605-12. https ://doi .org/10.5 455/pmb. 20100427030359

[17] Karadag G, Gungormus Z, Surucu R, et al. Awareness and practices regarding breast and cervical cancer among Turkish women in Gazientep. Asian Pac J Cancer Prev. 2014; 15: 1093-8. https : //doi.org/10.7314/APJCP.2014.15.3.1093

[18] Kanbur A, Capik C. Cervical cancer prevention, early diagnosisscreening methods and midwives/nurses role. Hacettepe University Health Science Faculty Nurs J. 2011; 18: 61-72.

[19] Markovic M, Kesic V, Topic L, et al. Barriers to cervical cancer screening: a qualitative study with women in Serbia. SocSci Med. 2005; 61: 2528-35. PMid:15953668 https ://doi.org/10.1016/ j.socscimed.2005.05.001

[20] Prolla D, da Silva S, Netto O, et al. Knowledge about breast cancer and hereditary breast cancer among nurses in a public hospital. Rev Lat Am Enfermagem. 2015; 23(1): 90-7. PMid:25806636 https://doi.org/10.1590/0104-1169.0185.2529

[21] Lemlem B, Sinishaw W, Hailu M, et al. Assessment of Knowledge of Breast Cancer and Screening Methods among Nurses in University Hospitals in Addis Ababa, Ethiopia, 2011. ISRN Oncol. 2013; 2013: 470981.

[22] Akhigbe O, Omuemu O. Knowledge, attitudes and practice of breast cancer screening among female health workers in a Nigerian ur- 
ban city. BMC Cancer. 2009; 9: 203. PMid:19555506 https: //doi.org/10.1186/1471-2407-9-203

[23] Seah M, Tan SM. Am I breast cancer smart? Assessing breast cancer knowledge among healthcare professionals. Singapore Medical Journal. 2007; 48(2): 58-162.

[24] Ahmed F, Mahmud S, Hatcher J, et al. Breast cancer risk factor knowledge among nurses in teaching hospitals of Karachi, Pakistan: A cross-sectional study. BMC Nursing. 2006; 5: 6. https : //doi.org/10.1186/1472-6955-5-6

[25] Altay B, Avci1 A, Rizalar S, et al. Breast and cervical cancer knowledge and awareness among University students. Asian Pac J Cancer Prev. 2015; 16(5): 1719-24. https://doi.org/10.7314/APJCP. 2015.16.5.1719

[26] Batiston P, Tamaki M, Souza A, et al. Conhecimento e práticasobreosfatores de riscopara o câncer de mama entre mulheres de 40 a 69 anos. Rev. Bras. Saúde Mater. Infant. 2011; 11(2): 163-71.

[27] Ndukwe G, Williams P, Sheppard V. Knowledge and perspectives of breast and cervical cancer screening among female African immigrants in the Washington D.C. metropolitan area. J Cancer Educ. 2013; 28(4): 748-54. PMid:23900622 https://doi .org/10.100 7/s13187-013-0521-x
[28] Poonam N, Nagaraj K, Nirgude S. Awareness of cervical cancer and effectiveness of educational intervention programme among nursing students in a rural area of Andhra Pradesh. Healthline. 2012; 3: 41-5.

[29] Joy T, Sathian B, Bhattarai C, et al. Awareness of cervix cancer risk factors in educated youth: a cross-sectional, questionnaire based survey in India, Nepal, and Sri Lanka. Asian Pac J Cancer Prev. 2011; 12: $1707-12$.

[30] Pham T, McPhee J. Knowledge, attitudes, and practices of breast and cervical cancer screening among Vietnamese women. J Cancer Educ. 1992; 7(4): 305-10. PMid:1305417 https://doi.org/10.1080/ 08858199209528187

[31] Pandey D, Vanya V, Bhagat S, et al. Awareness and attitude towards human papillomavirus (HPV) vaccine among medical students in a premier medical school in India. PLoS One. 2012; 7: 40619. PMid:22859950 https://doi.org/10.1371/journal. pone.0 040619

[32] Atwa A, Hassan H, Ahmed S. The impact of a hospital-based awareness program on the knowledge of patients about breast cancer and cancer cervix. International Journal of Studies in Nursing. 2019; 4(1): 20-29. https://doi.org/10.20849/ijsn.v4i1.537 